\title{
Stress Relaxation Behavior of Molten Slags
}

\author{
Taishi MATSUSHITA, ${ }^{1)}$ Yasushi SASAKI, ${ }^{2)}$ Mårten GÖRNERUP ${ }^{11}$ and Seshadri SEETHARAMAN ${ }^{11}$
}

1) Department of Materials Science and Engineering, Royal Institute of Technology, SE-100 44 Stockholm, Sweden. E-mail: taishi@kth.se $\quad$ 2) Formerly Division of Materials Science and Engineering, Hokkaido University, Kita-ku, Kita 13, Nishi 8, Sapporo 060-8628 Japan. Now at Department of Metallurgy, Tohoku University, 02 Aoba, Aramaki, Aoba-ku, Sendai 980-8579 Japan.

(Received on January 27, 2006; accepted on April 21, 2006)

\begin{abstract}
In the present work, a method to measure stress relaxation of molten slags, developed earlier by one of the authors, was applied to mould flux slags as well as synthetic slags. The molten slag was sandwiched by two Pt plates and was compressed. And stress relaxation tests (the structural relaxation of molten slags) have been conducted by compressing the molten slags as well as mould flux slags at strain rates of $10 \mathrm{~mm} / \mathrm{min}$. The results of stress relaxation tests were discussed from the viewpoint of relaxation time and structure of slags with the aid of Raman spectroscopy. The stress relaxation behavior is found to be linked to the structure of slags. The residual stress after a compression was increased with increasing of $\mathrm{Al}_{2} \mathrm{O}_{3}$ content and with decreasing of $\mathrm{CaF}_{2}$ content. The relaxation behavior was changed drastically with increasing of temperature for some molten slags.
\end{abstract}

KEY WORDS: stress relaxation; compressibility; molten slag; mould flux; structure of slag.

\section{Introduction}

The molten mould flux plays an important role in continuous casting of steel. The mould flux is introduced to prevent the reoxidation of steel. It acts as a lubricant between steel shell and mould, and medium for the transfer of heat from the solidifying steel shell to the mould. Optimizing the properties of the mould flux is one of the most important subjects. Many researchers were involved in this subject from the viewpoint of viscosity, thermal conductivity, etc.

Some researchers investigated the mechanical properties of slags. ${ }^{1-3)}$ In spite of the significance, however, the data on the mechanical properties of molten mould flux slags are scarce due to the difficulties involved in the experimentation. The liquid mould flux film between steel shell and mould in continuous casting process is compressed by ferrostatic pressure. In the process, the lubrication property must be affected by its compression stress and/or stress relaxation behavior. The optimization of mould flux properties toward high speed continuous casting is desired and the lubrication property is one of the most important factors.

In addition, generally, it is desired that thermal conductivity of mould flux is high for stainless steel and low in the case of mould flux for ordinary steel. Thus, thermal conductivity of mould flux slags need be properly tailored to suit the requirements of the process. The thermal conductivity of liquid slags depends on structure of slags and may be changed due to the structure change by the compression. The influence of compression on slag structure is of great relevance in the continuous casting process.

In the present study, compressibility test of molten slags was performed at high temperature. Correspondingly, the slag structure was investigated from the viewpoint of mechanical properties. If a certain pressure is applied to viscoelastic bodies in short time, the stress decreased from maximum point gradually with time and finally, it become zero or very low stress as equilibrium is established. This phenomenon, called stress relaxation was utilized in this study. Molten slags were compressed at the constant compression rate until a limiting value, after which the compression was stopped and the stress relaxation was observed. The molten slag compressive experiments were carried out at the facility available at Hokkaido University, Japan.

In addition to the compressibility tests, the slag structure was evaluated and was linked to results of compressibility tests. Various experimental methods, for example, Raman spectroscopy, IR, XRD, NMR are currently in use to investigate the slag structure. In this study, the slag structure was evaluated with the aid of Raman spectroscopy.

\section{Experiment}

\subsection{Sample Preparation}

In the present work, four different commercial mould flux slags as well as synthetic slags were used. The mould flux slags are designated as Flux A, B, C and D. These mould flux slags, were placed into graphite crucible, melted by induction furnace and poured onto a copper plate. The quenched glassy sample was crushed and placed on a Pt plate and it was melted with the aid of IR furnace for relaxation test (Fig. 1) in air.

Reagent grade $\mathrm{SiO}_{2}, \mathrm{Al}_{2} \mathrm{O}_{3}, \mathrm{CaCO}_{3}$ and $\mathrm{CaF}_{2}$ were used 


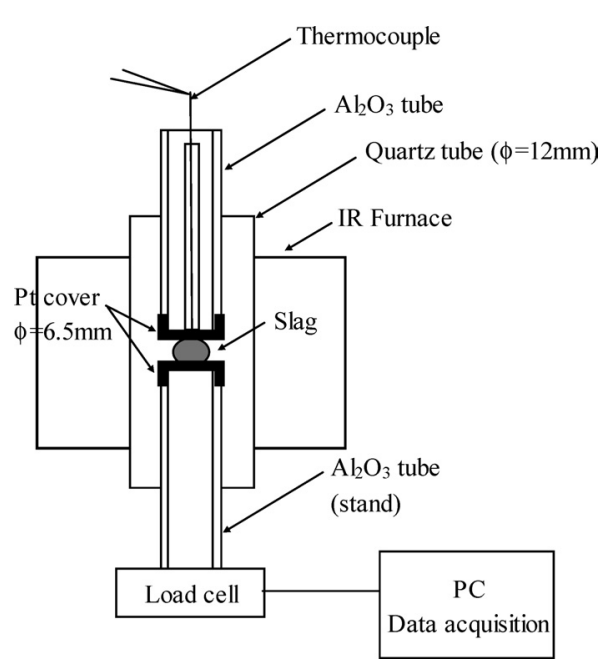

Fig. 1. Schematic illustration of experimental equipment.

Table 1. Chemical composition and properties of mould flux slags.

\begin{tabular}{lcccc}
\hline mass \% & Flux & Flux & Flux & Flux \\
& $\mathrm{A}$ & $\mathrm{B}$ & $\mathrm{C}$ & $\mathrm{D}$ \\
\hline $\mathrm{SiO}_{2}$ & 34.2 & 28.8 & 25.5 & 32.7 \\
$\mathrm{CaO}$ & 29.4 & 36.5 & 22.7 & 28.8 \\
$\mathrm{MgO}$ & 1.01 & 1.3 & 0.97 & 1.77 \\
$\mathrm{Al}_{2} \mathrm{O}_{3}$ & 3.92 & 6.5 & 12 & 4.7 \\
$\mathrm{TiO}_{2}$ & 0.1 & 0.3 & 0.46 & 0.11 \\
$\mathrm{Fe}_{2} \mathrm{O}_{3}$ & 1.09 & 0.8 & 2.86 & 1.24 \\
$\mathrm{MnO}$ & 0.05 & 3.3 & 0.04 & $<0.10$ \\
$\mathrm{Na}_{2} \mathrm{O}$ & 12.8 & 7.2 & 2.62 & 11.3 \\
$\mathrm{~K}_{2} \mathrm{O}$ & 0.37 & 0.1 & 1.43 & 0.31 \\
$\mathrm{LiO}_{2}$ & - & - & - & - \\
$\mathrm{F}$ & 7.95 & 5.9 & 4.42 & 9.4 \\
$\mathrm{CFree}_{\mathrm{CO}}$ & 3.6 & 1.5 & 17.7 & \\
$\mathrm{C}$ total & 7.9 & 8.8 & 9.4 & \\
Loss on ignition & 5.74 & & 20.3 & 6.6 \\
$\mathrm{H}_{2} \mathrm{O}$ & & 10.9 & & 14.1 \\
$\mathrm{Basicity}\left(\mathrm{CaO} / \mathrm{SiO}_{2}\right)$ & 0.89 & 1.27 & 0.93 & 0.88 \\
$\mathrm{Basicity}$ & & & & \\
$\left(\mathrm{CaO}+\mathrm{MgO} / \mathrm{SiO}_{2}+\mathrm{Al}_{2} \mathrm{O}_{3}\right)$ & 0.8 & 1.07 & 0.63 & 0.82 \\
\hline & & & & \\
\hline
\end{tabular}

Table 2. Chemical composition (weighted in amounts) of synthetic slags.

\begin{tabular}{cccccc}
\hline $\begin{array}{c}\mathrm{CaO} \\
\text { [mass\%] }\end{array}$ & $\begin{array}{c}\mathrm{Al}_{2} \mathrm{O}_{3} \\
{[\mathrm{mass} \%]}\end{array}$ & $\begin{array}{c}\mathrm{SiO}_{2} \\
{[\mathrm{mass} \%]}\end{array}$ & $\begin{array}{c}\mathrm{CaF}_{2} \\
{[\mathrm{mass} \%]}\end{array}$ & $\mathrm{CaO} / \mathrm{SiO}_{2}$ & $\mathrm{CaO} / \mathrm{Al}_{2} \mathrm{O}_{3}$ \\
\hline 38.6 & 20.4 & 41.0 & & 0.94 & 1.89 \\
30.3 & 37.4 & 32.3 & & 0.94 & 0.81 \\
28.0 & 14.8 & 57.2 & & 0.49 & 1.89 \\
36.3 & 19.2 & 38.5 & 6.0 & 0.94 & 1.89 \\
\hline
\end{tabular}

for the synthetic slags. Powders of $\mathrm{SiO}_{2}$ and $\mathrm{Al}_{2} \mathrm{O}_{3}$ were dried at $1073 \mathrm{~K}$ for $24 \mathrm{~h}$ in air and $\mathrm{CaCO}_{3}$ was heated at $1373 \mathrm{~K}$ for $24 \mathrm{~h}$ in air to decompose it to $\mathrm{CaO}$. The powders were then weighed to the desired compositions in required amounts, and the mixtures were melted in the same manner as mould flux by using IR furnace.

The initial composition of mould flux and synthetic slags are presented in Tables $\mathbf{1}$ and $\mathbf{2}$ respectively.

\subsection{Procedure}

Figure 1 shows the experimental apparatus which consists of an IR furnace, load cell and digital system (data logger). This IR furnace has the small focusing volume of about $1 \mathrm{~cm}^{3}$ just enough to heat the slag sample. The temperature of slag sample was measured by using the Type

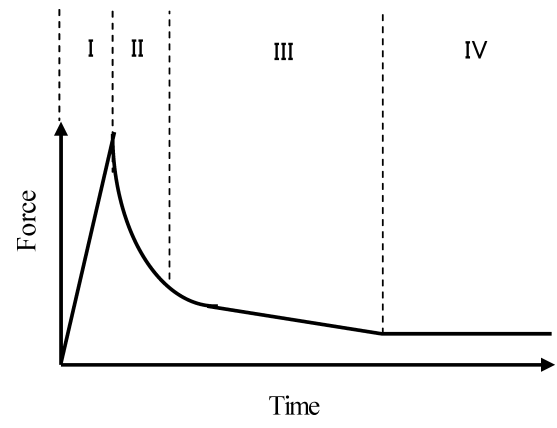

Fig. 2. Schematic illustration of results of stress relaxation test.

B thermocouple that was inserted into the upper alumina compression tube, located just above the upper Pt disk. The Micro Tester ${ }^{\mathrm{TM}}$ (Instron Co., load capacity: $1.0 \times 10^{-6}-2.0 \times 10^{3}[\mathrm{~N}]$, speed: $0.005-1500 \mathrm{~mm} / \mathrm{min}$ ) and its digital system were used to carry out the compression tests and data logging. In order to place and press the molten slag sample, the end of both alumina tubes were covered with Pt sheet ( $\varphi=6.5 \mathrm{~mm}, 0.2 \mathrm{~mm}$ thickness). No deformation of $\mathrm{Pt}$ sheet was observed during the experiments. Glass wool was packed between the alumina tube and $\mathrm{SiO}_{2}$ tube $(\varphi=12 \mathrm{~mm})$ to avoid the convection of air. Before the compression experiments, mould flux slag samples as well as the synthetic slags were melted by IR furnace and a sessile drop shaped sample was made by the premelting. After the samples were cooled down, the alumina tube of upper side was lowered slowly until its bottom surface (Pt cover) was in contact with the premelted sample. And the sample was heated up to the required temperature.

After reaching required temperature, the molten slag was sandwiched between two Pt plates and was compressed under air atmosphere. And stress relaxation (the structural relaxation of molten slags) tests were conducted by compressing the molten slags as well as mould flux slags at strain rates of $10 \mathrm{~mm} / \mathrm{min}$ until the particular compression (50\% compression) was reached. The measured force was registered by data logger and saved on a PC.

\section{Results}

A schematic view of result of stress relaxation test is shown in Fig. 2. The results of stress relaxation test can be classified as Stage I, II, III and IV. The force becomes maximum at maximum strain (Stage I). After this, the force decreased (Stage II) sharply. This phenomenon seems to be related to the elastic expansion of molten slag. And later, the force was decreased gradually (Stage III). It seems that the structural reconstruction of molten slags is related to this stage. The Stage II and III correspond to stress relaxation. After this, the stress becomes constant (Stage IV) and if the residual force does not prevail in the molten slag, it should be zero.

\subsection{Stress Relaxation Tests of Synthetic Slag}

Figure 3 shows the results of stress relaxation tests of synthetic slags at $1673 \mathrm{~K}$. In this experiment, the contact area of the sample is unknown. Hence, an apparent load (N) was used instead of stress. As mentioned in an earlier publi- 

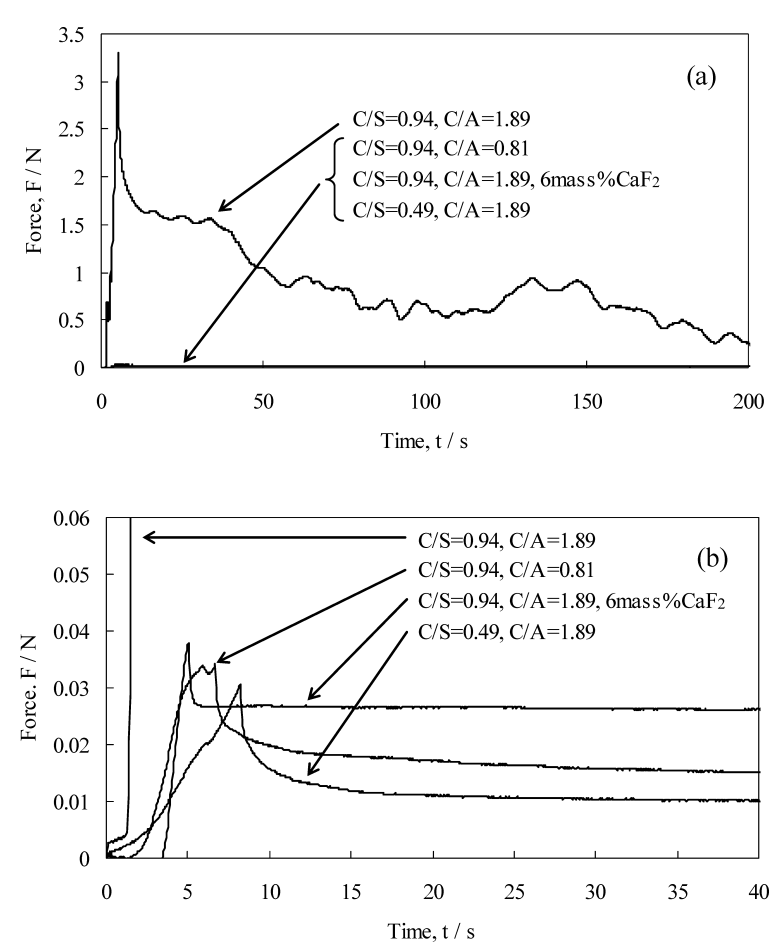

Fig. 3. Stress relaxation test of synthetic slags at $1673 \mathrm{~K}$. (a) Time: 0-200 s, (b) time: 0-40 s.

cation by Sasaki et al., ${ }^{4)}$ the influence of changing contact area is ignored in the case of relaxation test whereas the influence can not be ignored compression test case. As shown in Fig. 3(a), a high flow stress is observed for $\mathrm{CaO} / \mathrm{SiO}_{2}=0.94, \mathrm{CaO} / \mathrm{Al}_{2} \mathrm{O}_{3}=1.89$ slag (hereafter $\mathrm{CaO} /$ $\mathrm{SiO}_{2}$ and $\mathrm{CaO} / \mathrm{Al}_{2} \mathrm{O}_{3}$ are abbreviated as $\mathrm{C} / \mathrm{S}$ and $\mathrm{C} / \mathrm{A}$, respectively). And the stress relaxation behavior of other slags was similar within experimental error as shown in Fig. 3(b) (the exploded figure of Fig. 3(a)). The force decreased almost to zero after reaching the maximum force whereas in the case of some mould flux slags, the residual force was observed.

The stress relaxation behavior of the synthetic slags was also investigated at a higher temperature, viz., $1723 \mathrm{~K}$. This is shown in Fig. 4. It is seen that the stress relaxation behavior of $\mathrm{C} / \mathrm{S}=0.94, \mathrm{C} / \mathrm{S}=1.89$ slag was similar to other slags. On the other hand, the flow stress at $1723 \mathrm{~K}$ was found to be lower than that of $1673 \mathrm{~K}$ for the slag of $\mathrm{C} / \mathrm{S}=0.94, \mathrm{C} / \mathrm{A}=1.89$ and no significant change of stress relaxation behavior could be observed. It is likely that a structure change has taken place for the $\mathrm{C} / \mathrm{S}=0.94$, $\mathrm{C} / \mathrm{A}=1.89$ slag between $1673 \mathrm{~K}$ and $1723 \mathrm{~K}$.

\subsection{Stress Relaxation Tests of Mould Flux}

Figure 5 shows the results of stress relaxation tests of mould flux slags at $1473 \mathrm{~K}$. As shown in Fig. 5(a), the force does not go to zero immediately but gradually after compression for Flux A and B. In the case of Flux C, the force does not go to zero after compression within $300 \mathrm{~s}$ (test duration).

The force was increased monotonously before reaching the maximum force for Flux B and D. However, in the case of Flux $\mathrm{A}$ and $\mathrm{C}$, the force was decreased once before reaching the maximum force point and the force was increased again as shown in Fig. 5(b) (the exploded figure of
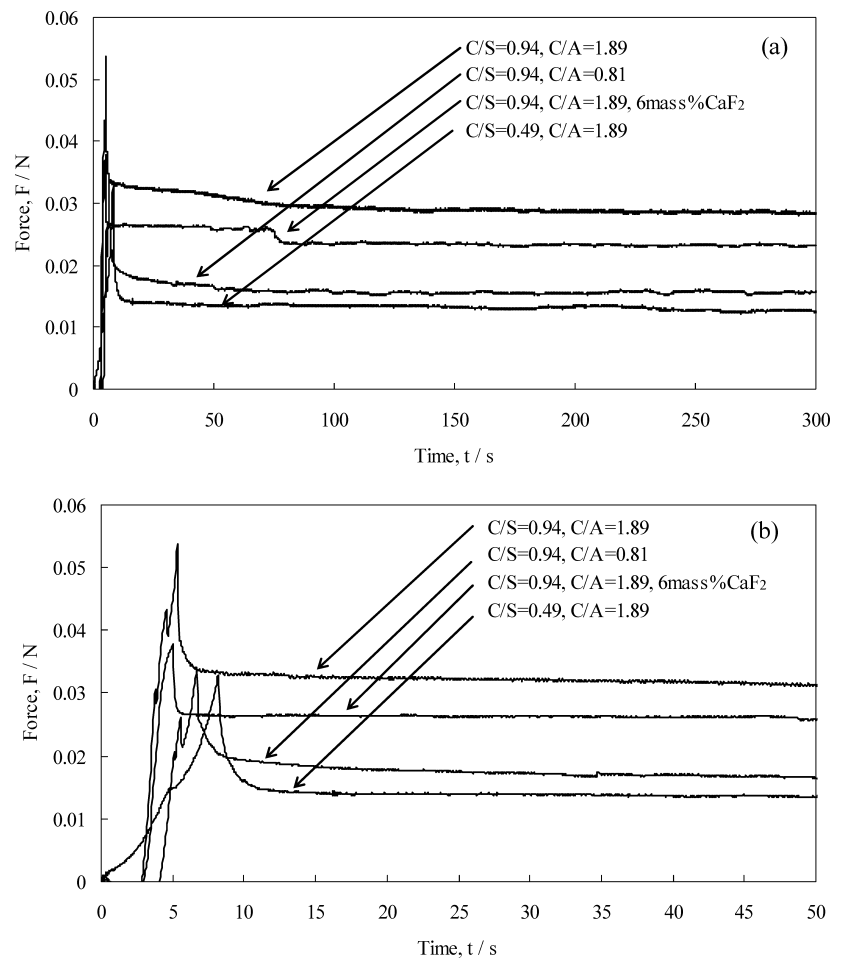

Fig. 4. Stress relaxation test of synthetic slags at $1723 \mathrm{~K}$. (a) Time: 0-300 s, (b) time: 0-50 s.
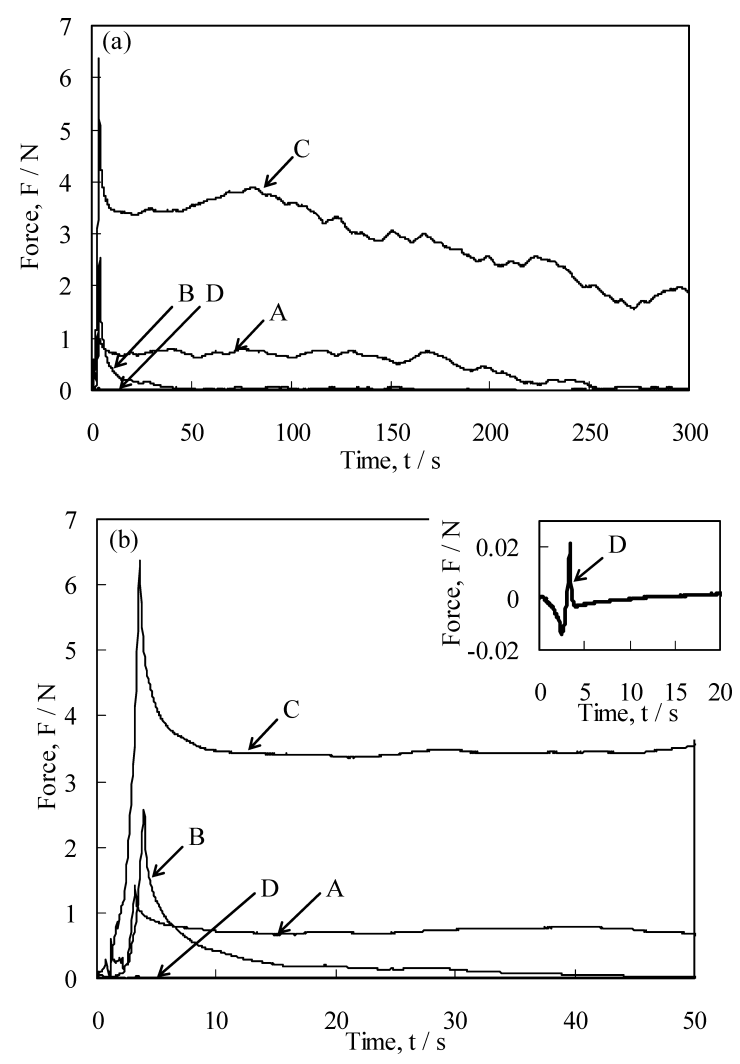

Fig. 5. Stress relaxation test of mould flux slags at $1473 \mathrm{~K}$. (a) Time: $0-300 \mathrm{~s}$, (b) time: $0-50 \mathrm{~s}$.

Fig. 5(a)).

The relaxation tests of mould flux slags have been carried out at $1523 \mathrm{~K}$ to investigate the temperature dependency. Figure 6 shows the results of stress relaxation tests of mould flux slags at $1523 \mathrm{~K}$. The significant change of stress relaxation behavior has not observed for Flux A, B as well 

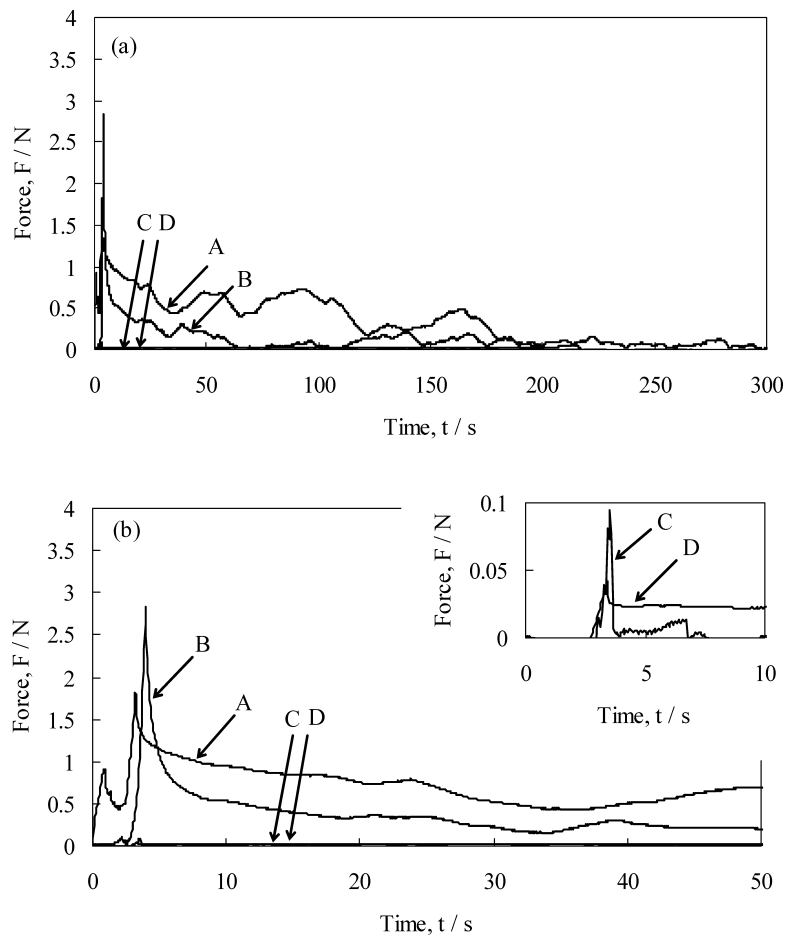

Fig. 6. Stress relaxation test of mould flux slags at $1523 \mathrm{~K}$. (a) Time: 0-300 s, (b) time: 0-50 s.

as $\mathrm{D}$ case. In the case of Flux $\mathrm{C}$, however, the force decreased significantly with a temperature increment of $50 \mathrm{~K}$. As shown in Figs. 5 and 6, the maximum force decreased from approximately 6.5 to $0.1 \mathrm{~N}$ and the residual force is also decreased from approximately 3.50 to $0 \mathrm{~N}$. In stage I, the force was increased again after the first decrease for some slags (ex. Flux A in Fig. 6). It is presumed that the stress relaxation has started partially before reaching maximum strain.

\subsection{Raman Spectroscopy Measurements}

The Raman spectra measurements have been carried out for synthetic slags as well as mould flux slags. Raman spectra measurements were carried out at room temperature. Quenched glassy slags were used for these measurements. The structure of silicate can be evaluated from the peak position of Raman spectra, i.e., the peak appeared at $850 \mathrm{~cm}^{-1}=$ monomer, $900 \mathrm{~cm}^{-1}=$ dimer, $950 \mathrm{~cm}^{-1}=$ chain and $1100 \mathrm{~cm}^{-1}=$ sheet. $^{5)}$

As shown in Fig. 7, the results of Raman spectroscopy for synthetic slags shows that all slags have chain structure $\left(950 \mathrm{~cm}^{-1}\right)$ although the peak for $\mathrm{C} / \mathrm{S}=0.49, \mathrm{C} / \mathrm{A}=1.89$ slag is shifted to higher value.

The results of Raman spectroscopy measurements for mould flux slags are shown in Fig. 8. The results of Raman spectra show that the Flux A and D have both monomer and chain structure. The Flux B has monomer structure whereas the Flux $\mathrm{C}$ has chain structure only.

\section{Discussion}

The behavior of the molten slag and molten mould flux seem to be affected by both viscosity and elasticity. The molten synthetic as well as mould flux slags were compressed to $50 \%$ of its height at rate of $10 \mathrm{~mm} / \mathrm{s}$. The relax-

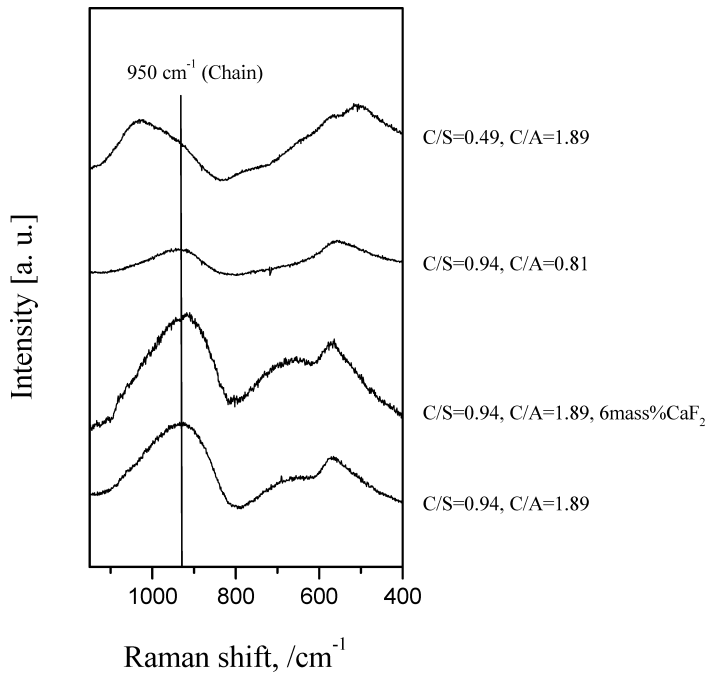

Fig. 7. Raman spectra of synthetic slags.

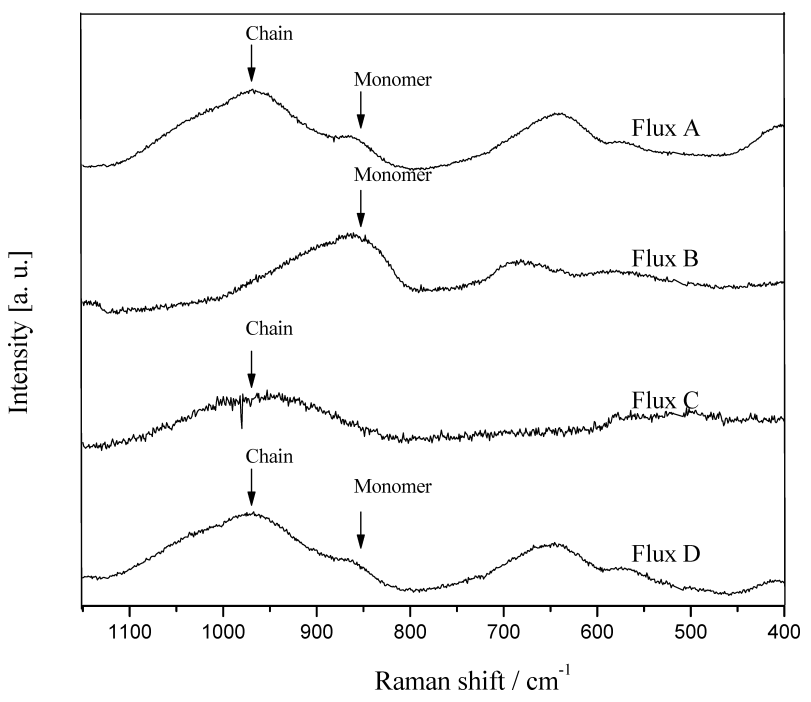

Fig. 8. Raman spectra of mould flux slags.

ation behaviors were observed and an attempt was made to understand the structure of molten slag and mould flux from the results.

\subsection{Stress Relaxation Behavior of Synthetic Slags}

As shown in Fig. 3, the stress relaxation behavior at $1673 \mathrm{~K}$ was significantly changed by the addition of $\mathrm{CaF}_{2}$ for $\mathrm{C} / \mathrm{S}=0.94, \mathrm{C} / \mathrm{A}=1.89$ slag. The structure of the molten slag with $\mathrm{C} / \mathrm{S}=0.94, \mathrm{C} / \mathrm{A}=1.89,6$ mass $\% \mathrm{CaF}_{2}$ seems to be rearranged more easily compared to $\mathrm{C} / \mathrm{S}=0.94, \mathrm{C} / \mathrm{A}=1.89$ slag due to the breaking of 3-D network of silicate by $\mathrm{CaF}_{2}$ and viscosity is decreased. The results of the Raman spectra measurements can be linked to the results of stress relaxation tests at $1723 \mathrm{~K}$. The stress relaxation behavior became almost same due to the fact that all slags have same structure. In other words, the slag structure can be estimated from the relaxation tests roughly.

However the relaxation behavior of $\mathrm{C} / \mathrm{S}=0.94, \mathrm{C} / \mathrm{A}=$ 1.89 slag at $1673 \mathrm{~K}$ can not be explained reasonably from the results of Raman spectra measurements. It is presumed that the result of Raman spectra is changed by the thermal history of slag. The time-temperature-transformation diagram (TTT figure) may be useful to discuss the relationship 
between thermal history and Raman spectra as well as slag structure. At present, it is difficult to link these results due to the lack of these data. Further studies to analyze the effect of the thermal history of slag on Raman spectra of quenched slags are currently considered.

\subsection{Stress Relaxation Behavior of Mould Flux Slags \\ 4.2.1. Composition Dependency}

From the stress relaxation test results of mould flux slags shown in Fig. 5, the force tended to become zero in short time with decrease of $\mathrm{Al}_{2} \mathrm{O}_{3}$ and increase of $\mathrm{CaF}_{2}$. The results were discussed from the view point of relaxation time, viz., Maxwell model. ${ }^{6}$ Maxwell model (which is a physical model) is represented by a spring and a dashpot connected in series. The "dashpot" is a cylindrical piston filled with viscous fluid. It is assumed that a certain strain is given to this model and keep the strain. First, the dashpot act as a rigid body and there is no deformation and the load on the spring is the only load. After this, the dashpot is deformed and the strain of dashpot is characterized by a stress relaxation time. In the case of relaxation test of viscoelastic bodies, the stress $\sigma(t)$ can be described following equation at time $t$.

$$
\sigma(t)=\sigma(0) e^{-(t / \tau)} \quad \text { where } \quad \tau=\eta / E(t) .
$$

where $\eta$ is viscosity, $E$ is relaxation modulus. The stress is maximum at $t=0$, and the stress is decreased with time exponentially. The relaxation time is defined as the time the stress becomes $\sigma(0) / e$ ( $e$ : base of natural logarithm (Napier constant)). In this study, the stress can not be measured because the cross section of the molten mould flux slag is changed with the displacement of Pt plate during the compression process and as mentioned above, the contact area change is unknown. Therefore the relaxation time is defined as the time the force become $F(0) / e(F(0)$ : maximum force).

The relaxation time of mould flux slags are shown in Table 3. The relaxation time is decreased in this order: Flux C, Flux A, Flux B, Flux D for 1473 K. As shown in Fig. 5, in the case of Flux A, the force was decreased suddenly until a certain stress and kept constant value for about $150 \mathrm{~s}$ and afterwards, the force decreased again. In the case of Flux $\mathrm{C}$, the force did not decrease up to $F(0) / e$ within the time-scale of this experiment.

These results can be explained from the view point of $\mathrm{Al}_{2} \mathrm{O}_{3}$ content and $\mathrm{CaF}_{2}$ content. Generally, the polymerization of silicate ions increases with increase of $\mathrm{Al}_{2} \mathrm{O}_{3}$ and decrease of $\mathrm{CaF}_{2}$. Therefore, it is presumed that the rearrangement of structure becomes more difficult with increase of $\mathrm{Al}_{2} \mathrm{O}_{3}$ and decrease of $\mathrm{CaF}_{2}$ due to the forming of 3 -D network of silicate. As a result, its high $\mathrm{Al}_{2} \mathrm{O}_{3}$ content and low $\mathrm{CaF}_{2}$ content lead to long relaxation time.

From the results of Raman spectra measurements, it is confirmed that the Flux $\mathrm{C}$ has large silicate net work than the other fluxes. As shown in Fig. 8, the Flux $\mathrm{C}$ has chain structure only. And the viscosity of mould fluxes were measured by cylinder rotation method. The viscosity of mould fluxes are shown in Fig. 9 as a function of temperature. ${ }^{7)}$ The viscosity of Flux $\mathrm{C}$ is higher than that of the other fluxes due to the large silicate network because of its high $\mathrm{Al}_{2} \mathrm{O}_{3}$ content and low $\mathrm{CaF}_{2}$ content. The liquidus
Table 3. Relaxation time of mould flux at $1473 \mathrm{~K}$ and $1523 \mathrm{~K}$.

\begin{tabular}{lcc}
\hline & $\begin{array}{c}\text { Relaxation time [s] } \\
(1473 \mathrm{~K})\end{array}$ & $\begin{array}{c}\text { Relaxation time [s] } \\
(1523 \mathrm{~K})\end{array}$ \\
\hline Flux A & 150 & 23.2 \\
Flux B & 1.80 & 1.15 \\
Flux C & $>300$ & 0.296 \\
Flux D & 0.10 & $>200$ \\
\hline
\end{tabular}

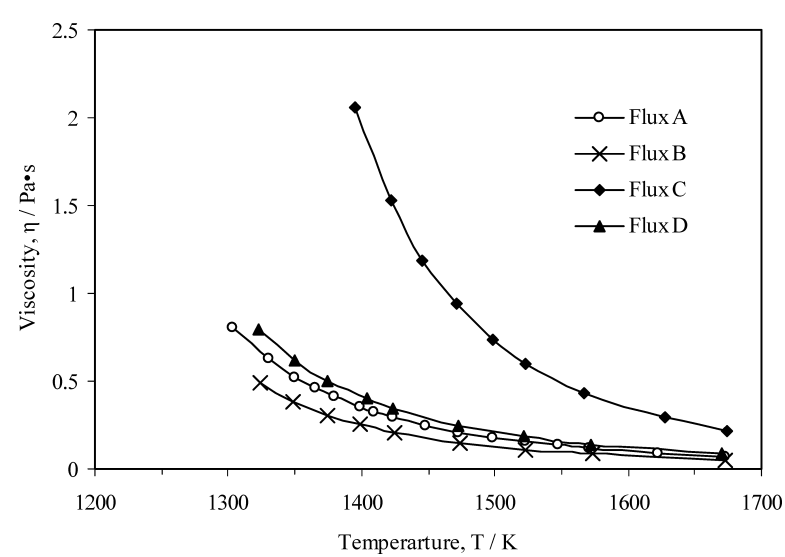

Fig. 9. Temperature dependency of the viscosity of mould fluxes.

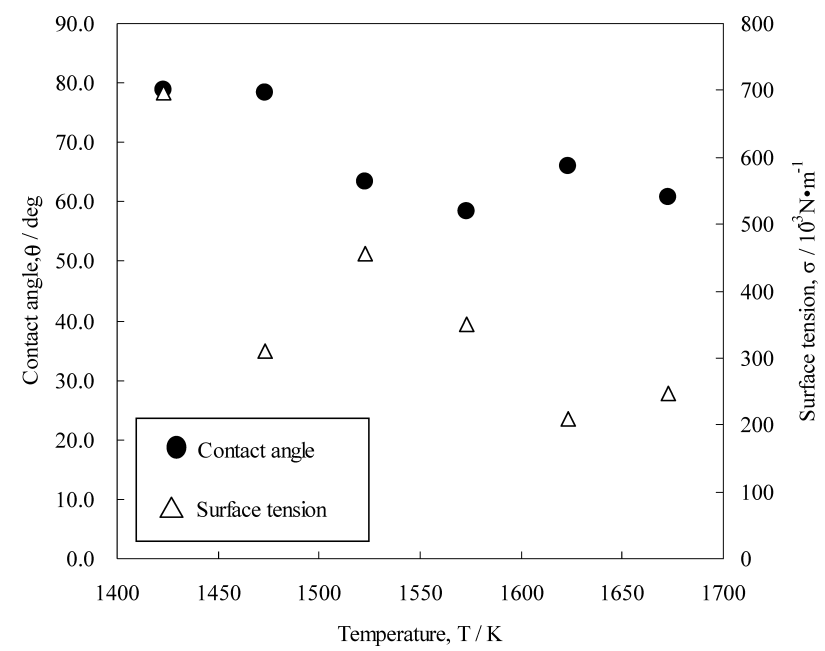

Fig. 10. Temperature dependency of contact angle and surface tension of Flux C (sessile drop method). ${ }^{9}$ )

temperature of mould fluxes were estimated from activation energies for viscous flow $^{8)}$ based on the experimental results shown in Fig. 9. From the second derivative plots of the activation energy for viscous flow, the liquidus temperature of mould fluxes are decreased in this order: Flux C, Flux D, Flux A, Flux B. The high liquidus temperature of mould flux $\mathrm{C}$ is corresponding to the high viscosity.

\subsubsection{Temperature Dependency}

As shown in Figs. 5 and 6, significant change of stress relaxation behavior was observed for Flux $\mathrm{C}$ with increasing of temperature. It is presumed that the structure change has been taken place. This supposition is supported by the fact that the contact angle and surface tension of Flux $\mathrm{C}$, measured by sessile drop method, ${ }^{9)}$ is changed drastically between $1473 \mathrm{~K}$ and $1523 \mathrm{~K}$ as shown in Fig. 10. In addition, the temperature dependency of viscosity of Flux $\mathrm{C}$ between $1473 \mathrm{~K}$ and $1523 \mathrm{~K}$ is steeper whereas the signifi- 
cant changes of viscosity, contact angle and surface tension have not been observed between these temperatures for Flux A, B and D (Fig. 9). From these experimental results, the slag structure of Flux $\mathrm{C}$ is apparently changed between $1473 \mathrm{~K}$ and $1523 \mathrm{~K}$ and it seems that the stress relaxation behavior is also changed due to the structure change and its relaxation behavior is also changed.

With regard to the temperature dependency on relaxation time, the latter was decreased with increasing of temperature except for Flux D (Table 3). According to Eq. (1), the relaxation time $\tau$ is decreased with decreasing of viscosity $\eta$. As shown in Fig. 9, the viscosity of mould fluxes were decreased with increasing of temperature. Therefore, the decreasing of the relaxation time with increasing of temperature is consistent with the results of viscosity measurement for Fluxes A-C.

The maximum force for Flux D was $0.042 \mathrm{~N}$ and the residual force was approximately $0.020-0.023 \mathrm{~N}$. And the relaxation time increased with increasing of temperature. More precisely, the residual force did not become less than $F(0) / e=0.015 \mathrm{~N}$ within the test duration as shown in Fig. 6(b) (upper right). As shown in the figure, the force is decreased suddenly from maximum force (after the strain is fixed). As mentioned earlier, the stress relaxation behavior was discussed based on the Maxwell model. However the sudden decrease of the force from the maximum force point can not be described by this model. It may not proper to evaluate the stress relaxation behavior with relaxation time (Maxwell model) for Flux D. It may possible to describe by another model, for instance, the three-parameter fluid model $^{10)}$ that consists of Voigt model (a spring and a dashpot connected in parallel) ${ }^{6)}$ and Maxwell model connected in series because the stress relaxation behavior can be described by the Maxwell model and the sharp decreasing of the force after the compression is stopped can be described by Voigt model.

\section{Conclusions}

The relaxation tests of molten mould flux slags and molten synthetic slags have been carried out with the aid of the furnace installed compression test machine. The relaxation behavior was changed with structure change as well as contact angle and surface tension. It is found that the rearrangement of structure becomes more difficult with increasing of $\mathrm{Al}_{2} \mathrm{O}_{3}$ and decreasing of $\mathrm{CaF}_{2}$ from the results of stress relaxation tests of mould flux slags. The stress relaxation behavior was explained reasonably from the results of Raman spectra measurements for mould flux and synthetic slags.

\section{REFERENCES}

1) Y. Sasaki, K. Ishii, D. Arahata and M. Iguchi: ISIJ Int., 40 (2000), 949.

2) D. B. Dingwell: Structure, Dynamics and Properties of Silicate Melts, ed. by J. F. Stebbins, P. F. MacMillan and D. B. Dingwell, Mineralogical Society of America, Washington, (1995), 21.

3) S. L. Web and D. B. Dingwell: Structure, Dynamics and Properties of Silicate Melts, ed. by J. F. Stebbins, P. F. MacMillan and D. B. Dingwell, Mineralogical Society of America, Washington, (1995), 95.

4) Y. Sasaki, M. Hino, H. Urata, M. Iguchi and K. Ishii: Proc. of the 3rd Int. Cong. on the Science and Technology of Steelmaking, AIST, Pennsylvania, (2005), 773.

5) B. O. Mysen, D. Virgo and C. M. Scaife: Am. Miner, 65 (1980), 690.

6) W. Flüge: Viscoelasticity 2nd Revised ed., Springer-Verlag, New York, (1975), 4.

7) T. Matsushita, M. Görnerup and S. Seetharaman: Proc. of the 7th Nordic-Japan Symp. Science and Technology of Process Metallurgy, Jernkontoret, Stockholm, (2005), 10: 1.

8) S. Seetharaman, S. Sridhar, Du Sichen and K. C. Mills: Metall. Mater. Trans. B, 31B (2000), 111.

9) T. Matsushita and S. Seetharaman: Unpublished work.

10) Y. Sasaki, H. Urata, M. Iguchi and M. Hino: ISIJ Int., 46 (2006), 385 . 